Etnográfica

Revista do Centro em Rede de Investigação em

Antropologia

vol. $16(2) \mid 2012$

Vol. $16(2)$

\title{
Marcus Banks e Jay Ruby (orgs.), Made To Be Seen: Perspectives on the History of Visual Anthropology
}

\section{Humberto Martins}

\section{(2) OpenEdition \\ Journals}

Edição electrónica

URL: https://journals.openedition.org/etnografica/1580

DOI: 10.4000/etnografica.1580

ISSN: 2182-2891

\section{Editora}

Centro em Rede de Investigação em Antropologia

\section{Edição impressa}

Data de publição: 1 junho 2012

Paginação: 428-430

ISSN: 0873-6561

\section{Refêrencia eletrónica}

Humberto Martins, «Marcus Banks e Jay Ruby (orgs.), Made To Be Seen: Perspectives on the History of Visual Anthropology», Etnográfica [Online], vol. 16 (2) | 2012, posto online no dia 26 junho 2012,

consultado o 12 fevereiro 2022. URL: http://journals.openedition.org/etnografica/1580 ; DOI: https:// doi.org/10.4000/etnografica.1580

Etnográfica is licensed under a Creative Commons Attribution-NonCommercial 4.0 International License. 
Pacífico Sul, e por isso, para os timorenses, as opções de política externa devem excluir uma escolha definitiva entre dois mundos.

A partir de um estudo de caso, a obra Translation, Society and Politics in Timor-Leste nos instiga a refletir sobre questões cruciais da antropologia. Nessa empreitada, a primeira crise pós-colonial (2006) em Timor-Leste, bem como o sistema de justiça, a política externa, o suporte material da tradução cultural, os mitos e as negociações matrimoniais são tomados pelos autores como arenas privilegiadas de tradução e negociação cultural. Zonas de contato, mundos culturais, fronteiras coloniais e pós-coloniais são temas exaustivamente debatidos, mas o investimento em pontes interdisciplinares tem sido tímido, apesar das interfaces com a linguística e a economia, por exemplo.

\section{Renata Nogueira da Silva}

Universidade de Brasília, Brasil

rerenogueira@yahoo.com.br
Marcus Banks e Jay Ruby (orgs.)

MADE TO BE SEEN:

PERSPECTIVES ON THE HISTORY OF VISUAL ANTHROPOLOGY

Chicago e Londres, University of Chicago Press, 2011 , 419 páginas, ISBN: 9780226036625.

Made to be Seen, organizado por Marcus Banks e Jay Ruby, aparece-nos como a mais recente tentativa de contar (um)a história da antropologia visual. É de registar e louvar, neste sentido, que vários dos autores convidados tenham o cuidado de referir que a antropologia visual tem "uma vida" que extravasa a das suas geografias académicas mais conhecidas, isto é, britânica, americana e francesa. A anotação é bem necessária, não só como forma de fazer emergir "espólios" escondidos nas várias histórias nacionais e regionais da antropologia, que ainda estão por contar, bem como para afirmar as interdisciplinaridades da mesma (não falando só da antropologia visual) que, como é amplamente referido, não se esgotam apenas noutras ciências, mas estendem os seus territórios às artes, à intervenção social e ao ativismo político. Ginsburg, por exemplo, acentua a importante dimensão política da autorrepresentação propiciada pelos média indígenas num capítulo cujo título é bem desafiador, "Native intelligence". O artigo de Faye Ginsburg é revelador de como produtos imagéticos enquadrados antropologicamente têm vindo a ser produzidos nas mais variadas latitudes existenciais do mundo (e não só recentemente), com fins que vão muito para além da produção, através das imagens, de conhecimento sobre o Outro. As imagens (sua produção e difusão) são vistas como recursos de poder e como discurso, ajudando à afirmação dos Outros e às suas reivindicações de se mostrarem e contarem através de processos editoriais por si (também) geridos. Este é, igualmente, um dos temas centrais do artigo de Elizabeth Edwards, abordado através de várias estórias e histórias da fotografia, num argumento alargado que faz equacionar a produção de conhecimento antropológico (visual) num quadro de colaborações e partilhas entre investigadores e sujeitos estudados.

A coletânea de textos, com a participação de alguns "consagrados" da disciplina, 
não repete ideias passadas. São dadas novas perspetivas que fazem situar algumas das preocupações e temas mais prementes da disciplina, a nível teórico, epistemológico e metodológico, abrindo linhas para o futuro da antropologia visual. Diria que a obra, em todos os seus contributos, não se apresentando como um manifesto, reivindica uma maior centralidade da disciplina no seio da antropologia social (e cultural). A referência ao esquecimento (ou será evitamento?) das suas virtudes epistemológicas, teóricas e metodológicas por parte dos "antropólogos não visuais” contribui, num certo sentido e contra a intenção original da obra (que é a de reforçar pontes e colaborações), para o reforço da autonomia (ou será isolamento?) dos antropólogos visuais. O capítulo final de síntese por Michael Herzfeld é crítico deste ponto, afirmando-se contra mais uma especialização da antropologia e propondo, talvez muito justamente, a aceção multissensorial de todo o projeto antropológico, num continuado desafio ao enunciado ocularcentrismo ou visualismo da disciplina. Como refere Herzfeld, fazendo-se situar na ambiguidade da sua própria desconfiança original face à utilização de imagens e à sua posterior adoção (com trabalhos audiovisuais já realizados), a antropologia implica-nos na utilização dos vários sentidos. Apesar de os formatos de apresentação dos resultados ainda não nos permitirem apelar ao multissensorialismo total (cheiros, toques...), não deixamos de nos envolver, em especial durante o trabalho de campo, através de várias experiências sensoriais que vão muito além da audição e da visão.

O livro reabre o debate sobre o que tem sido a antropologia visual nos últimos trinta anos e reconhece que, se a sua consolidação disciplinar acontece a partir do fim dos anos 70, com a crise da representação e do paradigma positivista nas ciências sociais, a sua história é muito mais longa e acompanha a da própria antropologia como um todo. Neste sentido, Banks e Ruby desafiam um lugar-comum discutido noutras obras de referência: o de que a história da antropologia visual se confunde com a história do filme etnográfico. Apesar de o capítulo de Jay Ruby e Matthew Durington voltar ao assunto (filme etnográfico), o livro propõe outras reflexões e âmbitos de estudo - fotografia (Elizabeth Edwards), produção e difusão dos média indígenas (Faye Ginsburg), teorização do corpo (Brenda Farnell), digital e hipermédia (Sarah Pink), arte e antropologia (Arnd Schneider), construção social do olhar e da visão (Cristina Grasseni, Sandra Dudley e Roxana Waterson), audiência e receção das imagens (Stephen Hughes) -, numa renovada tentativa de, de facto, não fechar e reduzir a antropologia visual ao âmbito de uma produção, receção e crítica do filme etnográfico ou documentário. E, na verdade, as referências de Ruby e Durington ao filme etnográfico são feitas no sentido de encontrar novos limites à sua definição, sem esquecer a importância das ligações teóricas e metodológicas à antropologia.

Um dos temas ou perguntas clássicas permanece subjacente aos diferentes escritos - o que fazer com o visual na antropologia social (e cultural)? A dificuldade na resposta ou nas respostas tem eco numa presença marginal das imagens (do audiovisual) no seio da antropologia social. Ainda que nas últimas décadas (desde os anos 80, principalmente) novos usos, por maior facilidade de acesso e menor custo de meios, tenham sido dados aos produtos audiovisuais, os autores fazem notar as insuficiências na presença do visual no seio da antropologia e a dificuldade de penetração dos seus produtos nas obras dos seus colegas antropólogos convencionais (itálico meu). Talvez, por isso, muitos dos diálogos sugeridos apontem a outras fronteiras, mais 
externas (ou não?) da antropologia (visual), apelando ao sensorial, às colaborações, aos aspetos materiais ou menos abstratos dos estudos das culturas e dos indivíduos, e à própria redefinição da relação entre sujeito e objeto, que passa, recuperando a aceção de Farnell com base na denominada "segunda revolução somática”, pelo reconhecimento de um sujeito com uma agencialidade em constante movimento, sujeita a circunstâncias em permanente mudança.

Igualmente não menos importante parece-me o reconhecimento das novas possibilidades técnicas com linguagens específicas, em particular de uma antropologia visual digital (Sarah Pink). Não "dizendo" nada de novo relativamente a textos recentes da autora, a verdade é que o facto de hoje ser mais fácil produzir e difundir imagens (com um mínimo de configuração antropológica), isto é, de existirem mais indivíduos a criar representações sobre culturas e indivíduos através de meios (computadores, Internet) e suportes (DVD) altamente acessíveis e acedidos é muito desafiador para todo o projeto antropológico, especialmente no sentido de implicar muito mais os auditores/leitores/espetadores na coautoria das interpretações ou análises produzidas. No entanto, se é verdade que o acesso a estas possibilidades técnicas se vê alargado, Pink salienta como deficitário o espetro dos trabalhos que, efetivamente, tiram proveito de todas as virtudes hipermédia disponíveis.
Finalmente, uma referência ao capítulo de Kathryn Ramey. A autora aborda vários filmes etnográficos experimentais, permitindo-nos reavaliar as fronteiras entre antropologia e arte e as relações entre antropólogos e outros profissionais do audiovisual. Salientando a incorporação da teoria antropológica em filmes "não antropológicos", Ramey faz referência às contribuições metodológicas, teóricas e epistemológicas desses filmes para a antropologia.

Em suma, a obra apresenta treze contributos que fazem alargar as perspetivas sobre a disciplina e relembram a necessidade de criticamente equacionar o ocularcentrismo predominante na ciência antropológica, ao mesmo tempo que clamam a favor de novas "utilidades" e "praticalidades" no uso do visual na antropologia. De referir, ainda, três outros recursos muito interessantes disponibilizados nesta publicação: primeiro, a sua extensa bibliografia de referência; segundo, a filmografia com indicação de distribuidor; terceiro, a clareza da escrita e do argumento ao longo das trezes participações, tornando o livro uma mui prática e útil ferramenta a ter em conta, não só pelos antropólogos (visuais), mas por qualquer cientista social.

\section{Humberto Martins}

Centro em Rede de Investigação em Antropologia, ISCTE - Instituto Universitário de Lisboa, Portugal humbmsm@yahoo.com 